\title{
The Stem Infusate and Ethanol Extract of Physalis angulata Inhibitory Activities against $\alpha$-Glucosidase and Xanthine Oxidase
}

\author{
Anthony Tjajaindra ${ }^{1}$, Anna Karmila Sari ${ }^{1}$, Adelina Simamora ${ }^{2,3}$, Kris Herawan Timotius ${ }^{2,3}$ \\ ${ }^{1}$ Faculty of Medicine and Health Sciences, Krida Wacana Christian University, Jakarta, Indonesia \\ ${ }^{2}$ Department of Biochemistry, Faculty of Medicine and Health Sciences, Krida Wacana Christian University, Jakarta, Indonesia \\ ${ }^{3}$ Centre for Enzyme Research in Health and Diseases, Krida Wacana Christian University, Jakarta, Indonesia
}

Background: Infusate of the whole plant of Physalis angulata is used traditionally for the remedy of various diseases including diabetes and gout. This study focused on the stem of $P$. angulata. The objectives of this study were to investigate the potential of the stem infusate (INPA) and ethanol extract (EEPA) of $P$. angulata as inhibitors of $\alpha$-glucosidase and xanthine oxidase.

Materials and Methods: INPA and EEPA were determined for their $\alpha$-glucosidase and xanthine oxidase inhibition activities in vitro, whereas antioxidant activity was determined by 2,2-diphenyl-1-picryl-hydrazyl-hydrate (DPPH) assay. Reference inhibitors were used for comparison. The total phenolic compounds were also estimated.

Results: EEPA had more concentrated phenolic than INPA which were 7.96 and $0.08 \mathrm{mgGAE} / \mathrm{g}$ dried biomass, respectively. INPA and EEPA inhibited $\alpha$-glucosidase considerably, with $\mathrm{IC}_{50}$ of 149.11 and $409.86 \mu \mathrm{g} / \mathrm{mL}$, respectively (acarbose was $130.66 \mu \mathrm{g} / \mathrm{mL}$ ). However, they inhibited xanthine oxidase weakly, with $\mathrm{IC}_{50}$ of 0.546 and $2.643 \mathrm{mg} / \mathrm{mL}$, respectively, compared with allopurinol $0.005 \mathrm{mg} / \mathrm{mL}$. EEPA scavenged DPPH radicals very weakly $(16.04 \mathrm{mg} / \mathrm{mL})$ compared to BHT $(0.021 \mathrm{mg} / \mathrm{mL})$, whereas no activity was observed for INPA.

Conclusion: The stem infusate and ethanol extract of $P$. angulata are able to inhibit the activity of $\alpha$-glucosidase, thus can be further explored for sources of bioactive compounds with $\alpha$-glucosidase inhibition activity.

Keywords: $\alpha$-glucosidase, infusate, ethanol extract, Physalis angulata, stem, xanthine oxidase

\section{Introduction}

Physalis angulata, (local name: ciplukan, nyoyoran, or cecendet) is a flowering plant of the family Solanaceae. It grows in the regions of South America and South East Asia. P. angulata is a shrub tree that can grow up to one meter. It has yellowish bell-shaped flowers, and its fruits were covered in a lantern-shaped leaves. $P$. angulata is known for its various health benefits. Traditionally, infusate of $P$. angulata was reported to cure various diseases, such as asthma, malaria, hepatitis, and diabetes mellitus. ${ }^{1}$ Pharmacological studies have been carried out to scientifically confirm the medicinal

Date of submission: May 11, 2021

Last Revised: July 6, 2021

Accepted for publication: July 8, 2021

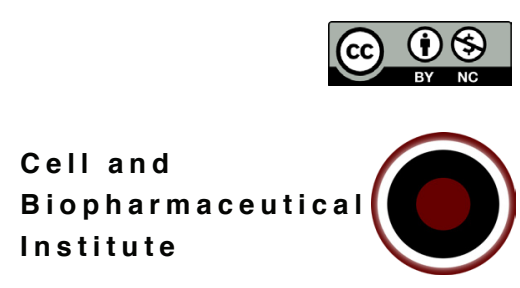

Corresponding Author:

Adelina Simamora

Department of Biochemistry, Faculty of Medicine and Health Sciences

Krida Wacana Christian University

J. Arjuna Utara No. 6, Kebon Jeruk, Jakarta, Indonesia

e-mail: adelina.simamora@ukrida.ac.id 
properties of $P$. angulata. Extracts of the aerial parts were reported for their antioxidant ${ }^{2,3}$, antimicrobial ${ }^{4}$, antitumor ${ }^{5}$, and anti-inflammatory activities ${ }^{6-8}$.

Type 2 Diabetes mellitus (T2DM) is one of the global epidemics and is projected to affect 700 million by $2030 .{ }^{9}$ T2DM is a chronic metabolic disease characterized by high level of post prandial blood glucose. This can be caused by insulin resistance or impaired pancreatic $\beta$-cells or a combination of both. Therapeutic strategy in controlling post-prandial blood glucose level includes inhibition against enzymes responsible for the degradation of dietary polysaccharides into glucose in the intestine. Thus, $\alpha$-glucosidase is targeted in the management of T2DM.

Cohort studies have demonstrated that hyperuricemia could increase the risk for developing T2DM. ${ }^{10}$ Hyperuricemia, a condition of high level of serum urate, may lead to gouty arthritis which is caused by the deposition of sodium urate in the joints. Xanthine oxidase is an enzyme involved in the oxidation of hypoxanthine to xanthine and from xanthine to uric acid. Inhibition on xanthine oxidase is the main therapeutic target in controlling serum urate.

As a home remedy, the whole plant of $P$. angulata is usually decocted or infused. However, the efficacy of the stem of $P$. angulata so far is not yet reported. Besides, studies are still few with regard to the antidiabetic and antihyperuricemia of the stem infusate of $P$. angulata. The present study describes the enzymes ( $\alpha$-glucosidase and xanthine oxidase) inhibitory and antioxidant activities of the stem extracts (infusate and ethanol extract) of $P$. angulata.

\section{Materials and methods}

\section{Chemicals}

Reagents used were of the highest purity, as follows: $\alpha$-glucosidase from Saccharomyces cerevisiae, xanthine oxidase from bovine milk, 1,1-diphenyl-2-picrylhydrazyl (DPPH) radicals, $p$-nitrophenyl $\alpha$-D-glucopyranoside, xanthine, acarbose, and allopurinol were obtained from Sigma-Aldrich (St Loius, USA). Solvents used were of analytical grade.

\section{Sample Collection and Extract Preparation}

$P$. angulata stems were collected from natural resources in Tangerang area (West Java) in May 2018. Stems were airdried and pulverized and kept at $4{ }^{\circ} \mathrm{C}$ until used. Infusate of $P$. angulata stem (INPA) was prepared by decocting the stem powder $(5 \mathrm{~g})$ in water $(150 \mathrm{~mL})$ at $90^{\circ} \mathrm{C}$ for 30 minutes.
Infusate was obtained by filtering the decoction, and the filtrate was freeze-dried to obtain solid material.

Ethanol extract of $P$. angulata (EEPA) was prepared by maceration of the stem powder $(30.60 \mathrm{~g})$ in ethanol for $72 \mathrm{~h}$. The mixture was filtered through filter paper, and the filtrate was dried under reduced pressure using a rotary evaporator.

Stock solutions of INPA and EEPA were prepared by dissolving each dried filtrate in DMSO.

\section{Determination of Total Phenolic Content (TPC)}

INPA and EEPA were determined for their phenolic contents based on the Folin-Ciocalteu method as reported previously. ${ }^{11}$ In brief, sample $(0.5 \mathrm{~mL})$ was mixed with Folin-Ciocalteu reagent $(10 \% \mathrm{v} / \mathrm{v}, 2.5 \mathrm{~mL})$, and left to stand for 10 mins. The mixture was then added with $\mathrm{Na}_{2} \mathrm{CO}_{3}(75$ $\mathrm{g} / \mathrm{L}, 2.5 \mathrm{~mL}$ ) and incubated at room temperature for $2 \mathrm{~h}$. The absorbance was measured at $765 \mathrm{~nm}$. TPC was estimated using a gallic acid calibration curve $(12.5-200 \mu \mathrm{g} / \mathrm{mL})$ and results were presented as $\mathrm{mg}$ gallic acid equivalent (mgGAE)/g dried biomass.

\section{Determination of a-glucosidase Inhibition Activity}

$\alpha$-Glucosidase inhibition activity of INPA and EEPA was determined based on a reported method. ${ }^{11}$ In this method, $p$-nitrophenyl glucopyranoside ( $p \mathrm{NPG}$ ) was used as a substrate and acarbose was used as a reference inhibitor. Sample of different concentrations $(50 \mu \mathrm{L})$ was mixed with $\alpha$-glucosidase $(0.5 \mathrm{U} / \mathrm{mL}, 50 \mu \mathrm{L})$ and phosphate buffer $(50 \mathrm{mM} \mathrm{pH} 6.8,50 \mu \mathrm{L})$. The mixture was pre incubated for 5 minutes at $37^{\circ} \mathrm{C}$, thereafter $p \mathrm{NPG}(1 \mathrm{mM}, 100 \mu \mathrm{L})$ was added. The reaction mixture was further incubated for 20 minutes at $37^{\circ} \mathrm{C}$. The reaction was interrupted by the addition of $\mathrm{Na}_{2} \mathrm{CO}_{3}(100 \mathrm{mM}, 750 \mu \mathrm{L})$ and the absorbance was measured on a spectrophotometer at $405 \mathrm{~nm}$. Inhibition percentage was calculated by the following equation: ( $\mathrm{A}$ $\mathrm{B}) / \mathrm{A} \times 100 \%$, where $\mathrm{A}$ is absorbance of control and $\mathrm{B}$ is absorbance of sample. Inhibition activity was presented as $\mathrm{IC}_{50}$ value, calculated from a linier regression equation of inhibition $\% v s$. sample concentration.

\section{Determination of Xanthine Oxidase Inhibition Activity}

Determination of xanthine oxidase inhibition activity was conducted following a reported method. ${ }^{12}$ Xanthine was used as a substrate and allopurinol was used as a reference inhibitor. Sample of different concentrations $(100 \mu \mathrm{L})$ was mixed with xanthine oxidase $(0.2 \mathrm{U} / \mathrm{mL}, 100 \mu \mathrm{L})$ and 
phosphate buffer $(50 \mathrm{mM} \mathrm{pH} 7.4,400 \mu \mathrm{L})$. The mixture was pre incubated for 5 minutes at $37^{\circ} \mathrm{C}$. Xanthine $(0.3 \mathrm{mM}, 200$ $\mu \mathrm{L})$ was added to start the reaction and the reaction mixture was further incubated for $30 \mathrm{mins}$ at $37^{\circ} \mathrm{C} . \mathrm{HCl}(0.1 \mathrm{M}, 200$ $\mu \mathrm{L}$ ) was added to stop the reaction and the absorbance was read at $290 \mathrm{~nm}$. Inhibition \% was calculated as follows: (A $-\mathrm{B}) / \mathrm{A} \times 100 \%$, where $\mathrm{A}$ is absorbance of control and $\mathrm{B}$ is absorbance of sample. Xanthine oxidase inhibition activity was presented as $\mathrm{IC}_{50}$ value which was calculated based on a regression equation (inhibition $\%$ vs. concentration).

\section{Determination of DPPH Radical Scavenging Activity}

Determination of DPPH radical scavenging activity was conducted according to a previous method. ${ }^{13} \mathrm{DPPH}$ solution in ethanol $(0.6 \mathrm{mM}, 3 \mathrm{~mL})$ was mixed with samples of different concentrations $(1 \mathrm{~mL}$ in ethanol). The reaction mixture was incubated in the dark at room temperature for 30 mins, thereafter the absorbance was measured at $517 \mathrm{~nm}$. The scavenging $\%$ was calculated by the following equation: $(\mathrm{A}-\mathrm{B}) / \mathrm{A} \times 100 \%$, where $\mathrm{A}$ is absorbance of control and $\mathrm{B}$ is absorbance of sample. DPPH radical scavenging activity was presented as $\mathrm{IC}_{50}$, calculated from a regression equation of scavenging \% plotted against sample concentrations.

\section{Statistical Analysis}

All experiments were conducted in three repetitions. Data were presented as mean \pm SD. Significance difference between samples were analysed using one-way ANOVA (analyzed by an SPSS v 23 (IBM Corporation, Armonk, NY, USA)) followed by a Post Hoc test (Tukey test). Values of $p<0.05$ were treated as significant.

\section{Results}

TPC

The TPC of INPA and EEPA were estimated by a spectrophotometric method, based on the complex formation of Prussian blue complex of $\left[\left(\mathrm{PMoW}_{11} \mathrm{O}_{4}\right)^{4-}\right]$ with phenolic compounds in the extracts. ${ }^{14}$ Linear regression of gallic acid standard curve obtained a good correlation coefficient with $R^{2}=0.998(\mathrm{y}=0.008 \mathrm{x}+0.034)$.

EEPA was found to have higher content of phenolic (7.96 $\pm 0.02 \mathrm{mgGAE} / \mathrm{g}$ dried biomass) compared to INPA (0.08 $\pm 0.00 \mathrm{mgGAE} / \mathrm{g}$ dried biomass).

\section{a-Glucosidase Inhibition Activity}

Both INPA and EEPA inhibited $\alpha$-glucosidase in a concentration-dependent manner. Inhibition activity (\% inhibition) increased with increasing extract concentration, Tabel 1. However, INPA exhibited strong inhibition on $\alpha$-glucosidase, comparable to that of the positive control acarbose. EEPA showed weaker activity compared to both INPA and acarbose $(p<0.05)$.

\section{Xanthine Oxidase Inhibition Activity}

Both INPA and EEPA were able to inhibit xanthine oxidase. Increased concentrations of extracts increased xanthine

Table 1. $\alpha$-Glucosidase inhibition activity of $P$. angulata stem extracts.

\begin{tabular}{lccc}
\hline Samples & $\begin{array}{c}\text { Concentrations } \\
(\boldsymbol{\mu g} / \mathbf{m L})\end{array}$ & $\begin{array}{c}\text { Inhibition } \\
(\mathbf{\%})\end{array}$ & $\begin{array}{c}\mathbf{I C}_{\mathbf{5 0}} \\
(\boldsymbol{\mu g} / \mathbf{m L})\end{array}$ \\
\hline INPA & 90 & $9.28 \pm 5.80$ & $149.11 \pm 7.46$ \\
& 135 & $33.41 \pm 5.91$ & \\
& 146 & $40.71 \pm 0.74$ & \\
& 158 & $58.21 \pm 2.87$ & \\
\hline EEPA & 180 & $84.49 \pm 3.34$ & \\
& 305.48 & $7.72 \pm 3.52$ & \\
& 374.46 & $13.57 \pm 2.27$ & \\
& 443.44 & $84.36 \pm 11.21$ & \\
\hline Acarbose & 522.27 & $97.38 \pm 0.55$ & \\
& 13 & $7.64 \pm 2.66$ & \\
& 26 & $19.54 \pm 3.00$ & \\
& 52 & $30.18 \pm 2.77$ & \\
& 208 & $66.66 \pm 1.44$ & \\
\hline
\end{tabular}


oxidase inhibition activity in a concentration-dependent manner, INPA showed higher inhibition activity than EEPA, yielding nearly five times higher activity for INPA than EEPA $(p<0.05)$ (Table 2). However, the activity of both extracts was much lower than allopurinol, the positive control.

\section{DPPH Radical Scavenging Activity}

DPPH assay was a versatile screening method in investigating the antioxidant activity of plant extracts. This antioxidant method is based on the scavenging activity of the extracts, probably by donation of hydrogen atom of the antioxidant compounds in the extracts to DPPH radicals. Increased INPA concentration ( 0.065 to $0.260 \mathrm{mg} / \mathrm{mL}$ ) did not change inhibition percentage significantly, indicating a very weak activity. The $\mathrm{IC}_{50}$ could not be determined. For EEPA, percentage of inhibition increased as a function of concentration. However, EEPA showed very weak scavenging activity as seen in the obtained $\mathrm{IC}_{50}$, compared to the positive control BHT (Table 3). BHT is a synthetic antioxidant and used as a food additive.

\section{Discussion}

Plant secondary metabolites, in particular polyphenolic compounds have been associated with the pharmacological activities of plant extracts, including antidiabetic ${ }^{15}$, antihyperuricemia ${ }^{16}$, and antioxidant ${ }^{17}$ activities.

Polarity of the solvent extractant is likely a decisive factor in the extraction of phenolic compounds in the plant parts. ${ }^{18}$ Findings in this study indicate that ethanol is more efficient than water in extracting phenolic compounds from the stem of P. acutangula. It is likely that heterogenous polar moieties attached to the phenolic derivatives of the stem of $P$. acutangula influence the solubility of the compounds in different solvents.

Inhibition on $\alpha$-glucosidase is one of important therapeutic strategies for the management of T2DM. Acarbose, the synthetic $\alpha$-glucosidase inhibitor, suffers from adverse side effects including gastrointestinal discomfort that may interfere its clinical use. ${ }^{19}$ Plants are potential source of natural $\alpha$-glucosidase inhibitor. For this purpose, $P$. angulata was investigated for its inhibition activity on $\alpha$-glucosidase. A number of studies have reported marked inhibition activity on $\alpha$-glucosidase by water ${ }^{20}$ and polar solvent extracts (methanol and ethanol extracts) ${ }^{21}$.

The current study exhibited that both INPA and EEPA were able to inhibit $\alpha$-glucosidase with comparable activity to acarbose, the reference standard. Antidiabetic activity of $P$. angulata has been studied previously using animal models, such as using whole plant, fruit, and leaves..$^{22-24}$ The current study added to the literature in which stem extracts were studied. It was revealed that $\alpha$-glucosidase inhibition activity of INPA and EEPA did not correlate with the phenolic contents of the stem extracts. These results suggest that the inhibition activity might also be attributed to the presence of non-phenolic compounds such as alkaloid and terpenoid, as also observed by others. ${ }^{25,26}$

Gout is a globally distributed disease with increasing prevalence. Hyperuricemia is the major risk factor for gout

Table 2. Xanthine oxidase inhibition activity of $P$. angulata stem extracts.

\begin{tabular}{lccc} 
Samples & $\begin{array}{c}\text { Concentrations } \\
(\boldsymbol{\mu g} / \mathbf{m L})\end{array}$ & $\begin{array}{c}\text { Inhibition } \\
(\mathbf{\%})\end{array}$ & $\begin{array}{c}\mathbf{I C}_{\mathbf{5 0}} \\
(\boldsymbol{\mu g} / \mathbf{m L})\end{array}$ \\
\hline INPA & 0.200 & $24.37 \pm 4.31$ & $0.546 \pm 0.03$ \\
& 0.500 & $47.77 \pm 11.19$ & \\
\hline EEPA & 0.624 & $63.20 \pm 8.43$ & \\
& 0.023 & $15.53 \pm 3.52$ & $2.643 \pm 0.28$ \\
& 0.375 & $47.82 \pm 2.23$ & \\
\hline Allopurinol & 6.757 & $80.81 \pm 3.25$ & \\
& 0.003 & $8.24 \pm 4.87$ & \\
& 0.004 & $36.71 \pm 5.93$ & \\
& 0.005 & $57.24 \pm 6.39$ & \\
& 0.007 & $64.59 \pm 8.00$ & \\
\hline
\end{tabular}


Table 3. DPPH radical scavenging activity of $P$. angulata stem extracts.

\begin{tabular}{lccc}
\hline Samples & $\begin{array}{c}\text { Concentrations } \\
(\boldsymbol{\mu g} / \mathbf{m L})\end{array}$ & $\begin{array}{c}\text { Inhibition } \\
(\%)\end{array}$ & $\begin{array}{c}\text { IC }_{\mathbf{5 0}} \\
(\boldsymbol{\mu g} / \mathbf{m L})\end{array}$ \\
\hline INPA & 0.065 & $27.66 \pm 0.49$ & Not able to be \\
& 0.195 & $29.45 \pm 1.42$ & $16.04 \pm 0.08$ \\
& 0.260 & $30.80 \pm 2.17$ & \\
\hline EEPA & 2.95 & $18.13 \pm 8.10$ & \\
& 5.91 & $22.43 \pm 1.50$ & \\
& 11.82 & $41.00 \pm 0.22$ & \\
\hline BHT & 17.73 & $53.69 \pm 1.59$ & \\
& 13 & $23.15 \pm 0.20$ & \\
& 26 & $40.99 \pm 0.59$ & \\
& 52 & $56.27 \pm 1.86$ & \\
& 208 & $60.58 \pm 1.47$ & \\
\hline
\end{tabular}

arthritis. Evidence from cohort study suggest association of hyperuricemia and diabetes mellitus. ${ }^{27}$ Currently, allopurinol is the first line drug prescribed to lower serum urate level by the inhibition on xanthine oxidase. However, its use was reportedly caused hypersensitivity reactions. ${ }^{28}$ The current study showed that INPA and EEPA were able to inhibit xanthine oxidase, although significantly more weakly than allopurinol. Similarly to $\alpha$-glucosidase inhibition activity, the observed inhibition activity on xanthine oxidase did not relate to the phenolic content in the extracts. This indicates the presence of non-phenolic based inhibitors. To the best of our knowledge, the current study is the first report on xanthine oxidase inhibition activity of $P$. angulata stem extracts.

Oxidative stress is generally defined as an imbalanced formation and removal of reactive oxygen species (ROS). ROS are capable of damaging various biomolecules, including protein, lipid, and DNA. Oxidative stress has been associated with the onset and progression of DM. Further, xanthine oxidase has been reported to increase during oxidative stress. ${ }^{29}$ Therefore, antioxidant is required to reduce the oxidative damage. INPA showed no radical scavenging activity, whereas EEPA had negligible activity.

The enzyme inhibition and radical scavenging activities observed in this study were weaker than those of standard compounds. This could be due to the crude extracts used in this study. The current study recommends for future studies to be directed on the use of successive extractions with solvents of varying polarity and the isolation of the bioactive compounds.

\section{Conclusion}

The study found that the ethanol extract of $P$. angulata (EEPA) had higher content of phenolic compounds than water extract (INPA). INPA and EEPA showed good inhibition activity on $\alpha$-glucosidase, with INPA exhibited higher activity than EEPA, comparable to that of acarbose. Both INPA and EEPA were weak inhibitors of xanthine oxidase compared to allopurinol. INPA and EEPA were found to be weak antioxidants.

\section{Acknowledgements}

Authors thank The Research Institute of Krida Wacana Christian University for the funding support (Grant number 20/UKKW/LPPM-FKIK/Lit/XII/2019). Authors are grateful to The Faculty of Medicine and Health Sciences Krida Wacana Christian University for the use of laboratory facilities. Authors also thank Mr Adit W. Santoso for general assists in the laboratory works.

\section{References}

1. Choi EM, Hwang JK. Investigations of anti-inflammatory and antinociceptive activities of Piper cubeba, Physalis angulata and Rosa hybrida. J Ethnopharmacol. 2003; 89 (1): 171-5.

2. Kusumaningtyas R, Laily N, Limandha P. Potential of ciplukan (Physalis angulata L.) as source of functional ingredient. Procedia Chem. 2015; 14: 367-72.

3. Susanti RF, Kurnia K, Vania A, Reynaldo IJ. Total phenol, flavanoid and antioxidant activity of Physalis angulata leaves extract by subcritical water extraction. Mod App Sci. 2015; 9 (7): 190-8.

4. Kumar V, Singh DK, Mohan S, Gundampati RK, Hasan SH. 
Photoinduced green synthesis of silver nanoparticles using aqueous extract of Physalis angulata and its antibacterial and antioxidant activity. J Environ Chem Eng. 2017; 5(1): 744-56.

5. Magalhães HIF, Torres MR, Costa-Lotufo LV, De Moraes MO, Pessoa C, Veras ML, et al. In-vitro and in-vivo antitumour activity of Physalins B and D from Physalis angulata. J Pharm Pharmacol. 2006; 58(2): 235-41.

6. Ukwubile CA, Oise IE. Analgesic and anti-inflammatory activity of Physalis angulata linn.(Solanaceae) leaf methanolic extract in swiss albino mice. Int Biol Biomed J. 2016; 2(4): 167-70.

7. Rivera DE, Ocampo YC, Castro JP, Barrios L, Diaz F, Franco LA. A screening of plants used in colombian traditional medicine revealed the anti-inflammatory potential of Physalis angulata calyces. Saudi J Biol Sci. 2019; 26(7): 1758-66.

8. Yang YJ, Yi L, Wang Q, Xie BB, Dong Y, Sha C-W. Anti-inflammatory effects of Physalin E from Physalis angulata on lipopolysaccharidestimulated RAW 264.7 cells through inhibition of NF-kB pathway. Immunopharmacol Immunotoxicol. 2017; 39(2): 74-9.

9. Nyenwe EA, Jerkins TW, Umpierrez GE, Kitabchi AE. Management of type 2 diabetes: evolving strategies for the treatment of patients with type 2 diabetes. Metabolism. 2011; 60(1): 1-23.

10. Woldeamlak B, Yirdaw K, Biadgo B. Hyperuricemia and its association with cardiovascular disease risk factors in type two diabetes mellitus patients at the University of Gondar Hospital, Northwest Ethiopia. EJIFCC. 2019; 30(3): 325-39.

11. Simamora A, Timotius KH, Santoso AW. Antidiabetic, antibacterial and antioxidant activities of different extracts from Brucea javanica (L.) Merr seeds. Pharmacogn J. 2019; 11(3): 479-85.

12. Simamora A, Santoso AW, Timotius KH, Rahayu I. Antioxidant activity, enzyme inhibition potentials, and phytochemical profiling of Premna serratifolia L. leaf extracts. Int J Food Scie. 2020; 2020: 3436940. doi: 10.1155/2020/3436940.

13. Kurniawan H, Dacamis ES, Simamora A, Tobing PSDL, Hanapiah A, Santoso AW. Antioxidant, antidiabetic, and anti-obesity potential of Ipomoea reptans Poir leaves. Borneo J Pharm. 2020; 3(4): 216-26.

14. Granato D, Santos JS, Maciel LG, Nunes DSJT. Chemical perspective and criticism on selected analytical methods used to estimate the total content of phenolic compounds in food matrices. Trends Anal Chem. 2016; 80: 266-79.

15. Salehi P, Asghari B, Esmaeili MA, Dehghan H, Ghazi I. $\alpha$-glucosidase and $\alpha$-amylase inhibitory effect and antioxidant activity of ten plant extracts traditionally used in Iran for diabetes. J Med Plants Res. 2013; 7(6): 257-66.

16. Lin S, Zhang G, Liao Y, Pan J, Gong D. Dietary flavonoids as xanthine oxidase inhibitors: structure-affinity and structure-activity relationships. J Agr Food Chem. 2015; 63(35): 7784-94.

17. Hatamnia AA, Abbaspour N, Darvishzadeh R. Antioxidant activity and phenolic profile of different parts of Bene (Pistacia atlantica subsp. kurdica) fruits. Food Chem. 2014; 145: 306-11.

18. Ahmed D, Fatima K, Saeed R. Analysis of phenolic and flavonoid contents, and the anti-oxidative potential and lipid peroxidation inhibitory activity of methanolic extract of Carissa opaca roots and its fractions in different solvents. Antioxidants. 2014; 3(4): 671-83.

19. Laube H. Acarbose: an update of its therapeutic use in diabetes treatment.. Clin Drug Invest. 2002; 22(3): 141-56.

20. Escandón-Rivera S, González-Andrade M, Bye R, Linares E, Navarrete As, Mata R. $\alpha$-glucosidase inhibitors from Brickellia cavanillesii. J Nat Prod. 2012; 75(5): 968-74.

21. Moradi-Afrapoli F, Asghari B, Saeidnia S, Ajani Y, Mirjani M, Malmir $\mathrm{M}$, et al. In vitro $\alpha$-glucosidase inhibitory activity of phenolic constituents from aerial parts of Polygonum hyrcanicum. Daru. 2012; 20(1): 37. doi: 10.1186/2008-2231-20-37.

22. Abo K, Lawal I. Antidiabetic activity of Physalis angulata extracts and fractions in alloxan-induced diabetic rats. J Adv Sci Res. 2013; 4(3): 32-6.

23. Raju P, Mamidala E. Anti-diabetic activity of compound isolated from Physalis angulata fruit extracts in alloxan induced diabetic rats. Amer J Sci Med Res. 2015; 1(1): 40-3.

24. Mafuyai C, Luka C, Jiyil M. Antidiabetic activity of Physalis angulata in streptozotocin induced diabetic wistar albino rats. J Adv Biol Biotechnol. 2020: 33-43.

25. Ji T, Li J, Su SL, Zhu ZH, Guo S, Qian DW, Duan JA. Identification and determination of the polyhydroxylated alkaloids compounds with $\alpha$-glucosidase inhibitor activity in mulberry leaves of different origins. Molecules. 2016; 21(2): 206. doi: 10.3390/ molecules21020206.

26. Fan $\mathrm{H}$, Chen $\mathrm{J}, \mathrm{Lv} \mathrm{H}, \mathrm{Ao} \mathrm{X}, \mathrm{Wu} \mathrm{Y}$, Ren $\mathrm{B}$, et al. Isolation and identification of terpenoids from chicory roots and their inhibitory activities against yeast $\alpha$-glucosidase. Eur Food Res Technol. 2017; 243(6): 1009-17.

27. Liu J, Tao L, Zhao Z, Mu Y, Zou D, Zhang J, et al. Two-year changes in hyperuricemia and risk of diabetes: a five-year prospective cohort study. J Diabetes Res. 2018; 2018: 6905720. doi: $10.1155 / 2018 / 6905720$.

28. Stamp LK, Day RO, Yun J. Allopurinol hypersensitivity: investigating the cause and minimizing the risk. Nat Rev Rheumatol. 2016; 12(4): 235-42.

29. Battelli MG, Bortolotti M, Polito L, Bolognesi A. The role of xanthine oxidoreductase and uric acid in metabolic syndrome. BBA Mol Basis Dis. 2018 ; 1864(8): 2557-65. 